\title{
Reflection in Learning
}

\author{
Bo Chang \\ Ball State University
}

\begin{abstract}
This study explored the impact of reflection on learning in an online learning environment. Twenty-five students from four online courses (two courses, each with two sessions) participated in this research project. Reflection was purposefully designed and embedded in various assignments. Data were mainly collected from interviews and students' various types of reflections. The inductive content analysis method was employed to analyze data. Five themes were generalized in terms of how reflection impacts learning: Increasing the depth of knowledge, identifying the areas which are missing or deficient, personalizing and contextualizing knowledge, providing comparative references in learning, and helping learners build structural connections in knowledge and social connections among learners. This study provides foundational ideas for designing reflective activities to promote students' learning in an online learning environment.
\end{abstract}

Keywords: Reflection, online learning, structure of knowledge

Chang, B. (2019). Reflection in learning. Online Learning, 23(1), 95-110.

doi:10.24059/olj.v23i1.1447

\section{Reflection in Learning}

Reflection plays an important role in the field of education. Scholars have discussed reflection from different perspectives for different purposes. For example, in Kolb's (1984) experiential learning model, reflection is the key for learners to transform concrete experience into abstract concepts. Schon (1987) differentiated the concepts of reflection on action and reflection in action. Reflection is also widely used in practice in various types of forms such as journals, portfolios, and reports (Helyer, 2015; Helyer \& Kay, 2015).

Many times, students complete their assignments without reflection. Reflection in learning is necessary for students to revisit what they have learned for improvement and for in-depth learning. It gives students an opportunity to document their learning journey and provide references and suggestions for future students. Through reflection, students will "become accomplished at recognizing that they are learning and building skills continuously" (Helyer, 2015. p. 23). In this study, the impact of reflection on learning in an online learning environment will be explored, which is less discussed in the literature. Specifically, the research question is: How does reflection impact learning and support learners to learn? 


\section{Review of Related Literature}

Scholars have widely discussed reflection and categorized reflection from different angles. Roskos, Vukelich, and Risko (2001) summarized the types of reflection discussed by scholars based on its function, structure, and timeline. Based on function, reflection includes personal reflection and classroom practice reflection; based on structure, reflection includes scaffolding, reframing, and debriefing; and based on a timeline, reflection includes retrospective reflection (reflecting on past actions), contemporaneous reflection (reflecting on the activities in-action), and anticipatory reflection (reflecting on future actions). Heyler (2015) suggested that:

Reflection is not just about looking back on what happened, it is encompassing. People instinctively reflect on events, perhaps to better understand what has happened and make sense of it; the idea of learning from the past, especially trying not to repeat mistakes is well established. (p.22)

Reflection enables learners to generalize the main ideas, principles, and abstract concepts from experience (Kolb, 1984). The process of reflection includes debriefing and reframing to expand students' beliefs and understanding, using journaling as a form of reflection to help students develop conscious awareness, and using prompts and feedback to guide students' reflection (Roskos, Vukelich, \& Risko, 2001). Clark and Brennan (1991) thought that reflective dialogue can facilitate learners to create knowledge and generalize practical examples into explicit knowledge. In reflective dialogue, students "integrate and generalize accepted arguments. They recapitulate actions and draw lessons from their experiences" (Schwarz, Dreyfus \& Hershkowits 2004, p. 170), and help students draw conclusions. In reflection, experience is re-thought in order for the perspective to change and the practice to improve (Freed, n. d.). For Lin, Hmelo, Kinzer, and Secules (1999), "reflective thinking is an active, intentional, and purposeful process of exploration, discovery, and learning" (p. 46). They stated that:

In order to make conscious decisions about the uses of information, students have to step back and reflect on how they actually make decisions and solve problems and how a particular set of problem-solving strategies is appropriate or might be improved. (p. 43)

Reflection is to evaluate, synthesize, and abstract the concrete examples shared. It reveals the important features and relations which are neglected in abstract and explicit knowledge.

Agouridas and Race (2007) said that reflection is a process of personalizing and understanding the contents, process, and the rationales for what we have learned. Through reflection, we relate our personal experience to a wider perspective, which helps us to see the bigger picture. Helyer, (2015) stated that the process of reflection utilizes knowledge that "lies deep within (tacit knowledge) - so deep it is often taken for granted and not explicitly acknowledged, but it is the data humans use to make instinctive decisions based upon accumulated knowledge from past actions and experience" (p.22). Winitzky (1992) viewed reflection as a process to retrieve, apply, and analyze knowledge, and to relate that knowledge to larger issues. Agouridas and Race (2007) also agreed that we can step back and reflect on the process of assignments and think of their broader meanings.

Larsen, London, and Emke (2016) argued that reflection is not just for social purpose, it can also be used to "influence students' learning from experience, increase their awareness of their thoughts and actions, and increase their perceived recall of experiences" (p. 285). When students conduct the reflections, they repeatedly retrieve the information from memory, and the retention of experience is thereby increased. 
Reflection stimulates students to question their philosophy and beliefs and make connections between students' beliefs and their assignments, and to tie theory to students' personal beliefs. "Developing a reflection means that an individual begins to automatically challenge and question why tasks were undertaken in a certain way rather than how they were carried out (Helyer, 2015, p.23). Ovens and Tinning (2009) believed that through engaging in reflective activity, students "could begin to peel back some of the layers of their social reality" (p.1130) and search for the social structures which have contributed to their oppression.

Reflection is not just an individual activity. Reflection can also be a collective activity. "Joint reflection with peers aids individuals as they refine, develop, and enhance teaching skills from various perspectives" (Krutka, Bergman, Flores, Mason, \& Jack, 2014, p. 85). Collaborative reflection can bring different perspectives when we have dialogues with others, when others see things differently, ask different questions, or challenge our assumptions (Krutka, et. al., 2014). In the collective reflection, "We interpret what we do and why we do it by involving ourselves and others in conversation, debate, and reflection on individual and collective understandings. We value the importance and relationships of all parties involved" (Bowne, Cutler, DeBates, Gilkerson, \& Stremmel, 2010, p. 49).

Larsen, London, and Emke's (2016) research indicates that in reflection processes, learners can exchange perspectives among group members and reevaluate their original perspectives. Different perspectives and alternative ways of solving problems can be generated in this dialogic reflection process.

Learners can reflect on both professional issues and private issues. Reflection "without connection to course material will not result in learning" (Roberts, 2008, p.125). Reflecting on the professional level is important. However, it is also necessary to reflect on private issues since through reflecting on private issues and sharing each other's personal experiences, learners will find more connections and a sense of safety and belonging, and they can also provide each other social support in this process (Nilsson, Andersson, \& Blomqvist, 2017). Roberts (2008) reminded us though, that reflection may veer off into too emotional and uncomfortable topics, which can cause ethical issues if the information is misused.

To support reflection, educators can help learners externalize their tacit mental activities by prompting them to reflect on what they have done before, during, or after an event (Lin et al., 1999). Learners can create portfolios to reflect on their professional work and make their concrete practice visible. "The reflective comments expected in teaching portfolios are articulations of identity in practice and negotiations of the repertoires of the community" (Berrill, \& Addison, 2010, p. 1180). Reflecting on learners" experience "enables the participants to create and share local explicit and tacit knowledge" (Gausdal, 2008, p. 211). Scholars used writing formats such as portfolios, summaries, journals, etc. to reflect on experience (Roskos, Vukelich, \& Risko, 2001). They found out that interactive reflection can lead learners to more in-depth ideas. They recommended that instructors design the instructional protocols to help students develop reflective thinking. Yaffe (2010) recommended to improve self-awareness and reflective ability through different stages of reflections: Learners started with self-reflection through video-taping the lessons from their perspectives. Both mentors and learners then watched the recorded lessons and identified the strengths and weaknesses of learners' practical tasks and looked for alternatives and ways in which the tasks could be improved. The purpose was to improve the ability of learners to reach to a higher level of reflection, increase their self-awareness in their work, and make their implicit knowledge explicit. 
Cavilla's (2017) study indicates that reflection may affect students' affective levels, but not necessarily their cognitive levels. To make reflection useful for students' academic performance, reflection "should be implemented in a well-structured, intentional manner with purposeful fidelity throughout the course of a student's academic career" (p. 12). Persson, Kvist, and Ekelin's (2018) research shows that students may not be honest about their reflections when they adjusted them to suit the needs of the instructors. Therefore, the researchers suggested that reflection be used for the purpose of development without assigning credit points so that students feel safe to provide their honest reflection.

\section{Methods}

This research project was conducted in a public research university in the Midwestern United States. Twenty-five graduate students from the online courses (two courses, each with two sessions) participated in this research project. The first course is about the foundations of adult and community education, and the second is about adult learning theories. Even though the assignments in these courses were different, the requirements for reflection were nearly the same. The study was reviewed and approved by the University Institutional Review Board. Participating in this research project was voluntary, and the participants could withdraw from the project at any time.

\section{Design and Procedures of the Intervention}

Based on the ideas of reflection in literature, various reflections were designed to meet learners' professional and private/emotional needs. At the professional level, to help students understand the values of assignments and how these can contribute to their professional work, reflection was embedded into the assignments.

The followings are the specific procedures in the reflection design:

First, after students completed each assignment, they were required to reflect on contentspecific knowledge, their learning processes, and the value of their learning. Specifically, at the end of each assignment, students were required to reflect on the highlights, or the uniqueness, or the most significant parts of their assignment, the process of how they completed their assignments, the lessons/tips they gained in this process, and on other information they wanted to share. To reinforce their learning, students were also required to summarize the main ideas of each assignment in a summary table. Such reflection serves as an evaluation of students' assignments and helps students check to see whether or not they have completed every required task in the assignments.

Secondly, students completed a midterm course reflection and a final course reflection about their opinions of the online discussions, the group projects, the knowledge and skills they learned in the course, and their overall impression of the course, etc. These reflections mainly served as feedback for course improvement and for students to review what they had learned.

Thirdly, students reflected on the following in their final project demonstration: their learning experience, their learning process (reflecting on past actions), the highlights/the uniqueness/creative aspects and the most significant parts of their project (reflecting on the activities in action), and the lessons/tips they gained from their whole project. They also reflected on their survival tips for the course, their learning journey during the semester, lessons they had 
gained, knowledge they had learned, and their suggestions for future students (reflection on future actions). These reflections were recorded in videos and posted publicly on their group blogs.

The above reflections include both "reflection on past," "reflection in action," and "reflection on future actions"; academic/profession related reflection, such as reflection embedded at the end of each assignment for the purpose of conceptualizing students' learning, and private reflection, such as learning journey and survival tips, for the purpose of providing students social and emotional support and creating a sense of community and connection. To promote the group reflection, students were required to submit all of their assignments to their group blogs so that other students could access and comment on their work and at the same time learn different perspectives from their reflections about how they conducted their project. To provide some private space, students were required to submit the final reflection paper privately to the instructor.

\section{Data Collection and Analysis}

Data mainly included interviews and participants' various types of reflections. These included individual students' mid-term course reflections, final reflection papers, as well as students' responses to the questions about reflective dialogue in the online discussions. In interviewing students, I (the instructor for these courses too) asked students' opinions of reflection on their learning. I also reflected on the instructional practices in previous courses, in the current courses, and on possible changes to future courses with the students I interviewed. As part of the online discussion questions, students were required to discuss what they had learned from the courses. This type of reflective dialogue is to help students generalize their experiences and draw lessons from them. Other questions that I asked the participants in interviews and in written reflection included: How do you think this type of reflective dialogue can help you understand the topics in this course? After you did each assignment, what have you gained, what was the value about this assignment? What lessons have you gained, what knowledge did you learn? What else can we do to improve this type of reflective dialogue?

The inductive content analysis method was used to analyze data. Such analysis includes using open coding (labeling the chunks of data based on summarizing the meaning of the text), creating categories (grouping the labels based on their similarities and differences), and using abstraction (generalizing themes based on the categories created) (Elo \& Kyngäs, 2008). Specifically, I read the data, highlighted the segments of the data which were relevant to the research questions, I then put these highlighted data in Excel, summarized the meanings of these data, and used a set of codes to label these data and to reduce the volume of data. I then grouped the data segments with similar codes and categorized them. Based on the categories created, I generalized the themes.

\section{Results}

Six themes were generalized in terms of how reflection impacts learning: Increasing the depth of knowledge, identifying the areas which are missing or deficient, personalizing and contextualizing knowledge, providing comparative references in learning, helping learners build structural connections in knowledge, and social connections among learners. Generalization here is an abstraction process through which we draw general conclusions/principles based on particulars. It is part of the inductive analysis process (Polit \& Beck, 2010). 
In reporting the data, I did not indicate how many participants provided similar data since some data may have been provided by one or two learners, but represented what commonly occurred in the courses, or indicated the unique situation in the courses since I as an instructor have the local rich knowledge of the specific circumstances in the courses. As the instrument of the qualitative research, I as a researcher play a role in understanding what is common or what is unique in these courses based on my observations of the courses, my experience of interacting with students, and the issues as they occurred in these courses.

\section{Reinforcing and Deepening Knowledge through Revisiting the Knowledge Learned}

Reflection was required at the end of each assignment. Students reflected on the process of each of their assignments and on the value of their assignments. Through reviewing and revisiting the knowledge learned, some students thought that their new knowledge had been reinforced and deepened. One student said:

The reflection at the end of the evaluation assignment was beneficial because it was like getting a high light on what was just done. You can write something down and not pay much attention on it till later, but by putting the reflection section on the end it almost forced you to look at what you did, kind of digested what was just accomplished.

This was echoed by another student who thought that reflection made students think about the assignments more deeply after they looked back and analyzed what they had completed:

Reflections helped me understand the assignments because I thought about them more deeply. It made me analyze the theories a little more because I revisited them after the assignments were completed. I think that it is a good learning tool to come back to a theory after learning about it, so that you can analyze it and see if it was effective in a real-life situation.

One student also mentioned that through reflection, students could look back to what they had completed and understand the applicative aspect of the knowledge:

The reflections allowed me the chance to really take a breath and look back on what our group had just completed. This was welcome because when working I sometimes forgot to really think about exactly what I just did. By completing these reflections, I was able to really know how to apply what I just learned in real world applications and programs.

Reflection activity allows students to conceptualize the experience, and raise the knowledge to a higher level meta-cognitive aspect. As one student said, "the section on Reflections helped me to see my own meta-cognition."

\section{Improving Learning by Identifying the Areas Which Are Missing or Deficient}

Reflection helped students improve their work. The participants thought that reflection helped them to self-evaluate/assess the knowledge they had acquired and to identify the unclear areas in learning. One student said that he appreciated the reflection portion at the end of the assignment, since it made students look back at their efforts and see how they could improve their learning in the future. One student said that after he completed his assignment, he reflected back on what he had done and realized that maybe some pieces could be completed better next time. One student said that "The reflections helped me with identifying the areas of our project where more clarification was needed." Most of the students noticed that reflection allowed them to step 
back to review all of the knowledge they had learned and to see the value of their work holistically, not just partially. One student said:

The reflections were a great part of looking back on what I had learned and how I had reached that point in the project and my understanding. I was able to identify ways to improve the group's cohesiveness and the overall progression of our work by reflecting on our efforts.

Reflection is a good way for students to look back on their work to evaluate and identify what is missing, just like one student said:

I thought the reflection part of the assignments was a good way for groups to assess their experience through the specific assignment and what could be done better for the next one. After reviewing ours, I do wish we had reflected on different aspects for each assignment. It seemed that our group had to focus a lot on trying to maintain productive communication to successfully complete each assignment. Even though communication is important, it would have been nice to be able to focus on other aspects.

Some students thought that reflection embedded in the assignments provided them opportunities to make changes to improve their work while they looked back at what they had completed. Through reflection, they could find out the best way to do things. One student said:

The reflection piece was a good way to look inside myself and see what I felt was working well and what was not. It also allowed me time to reflect so I could make any changes necessary to better the situation moving forward. I realized through the reflections that so much of this field is trial and error. Being open to finding out what will work and what will not but being flexible enough to try new things.

Reflections shared in the group blogs allowed other students to understand each group's projects and provide meaningful feedback to their peers for improvement. One student said:

I appreciated the reflections at the conclusion of most assignments. It always beneficial to look back at your efforts and see how you could improve in the future. These reflections also allow for purposeful feedback to help create meaning for the learner. This reflection piece is significant for any type of learning to take place, and it also holds true with the course.

\section{Personalizing and Contextualizing Knowledge}

Students were required to reflect on what they had learned from their own projects in their assignments, and what they had learned from other groups in their final survival memo - students' reflections of how they successfully completed the course and "survived" during the semester. Some students said that the reflection part of each assignment was their favorite part, since it gave them an opportunity to write about their learning process and about what they gained from it. By describing their learning journey in their reflections, students were able to personalize or contextualize the knowledge and transform their implicit knowledge into explicit knowledge.

Some students described the process of how they completed their assignments with personal experiences and emotions, how they understood the theories, and how they transformed the theories into concrete practical programs. Some participants said that by looking at others' reflections, blogs and projects, they could see the theories and how they could be used in practice. One student said: 
I also think that reflecting on others' projects helped me to think more critically about the learning theories and how they were being applied which helped me to understand the other theories better.

First-hand experience described by students provides the concrete context for other students to understand the applicative aspects of the theories. One student said:

The reflections in each assignment helped me to understand the assignment in regards to how the theories and ideas were applied in a practical sense. There were very detailed descriptions from other classmates in regards to how they applied different techniques and methods in their study. It is always nice to get first-hand experience from my peers versus reading about it in a textbook.

Students were required to make video introductions about how they completed their projects. One student said that reflective practice really made him go back to look at what he had talked about in his video introduction of the project and find out the information which was important. He said that when he reflected on what he did, he thought of the personal connections with the community he had and how his past experiences connected to his current situation. He drew all of these together through reflection. Reflection allowed him to tie what he had learned to the community where he had personal connections and meshed his personal knowledge about community together with the theories he had learned and the project he had completed, which helped him understand knowledge in context. This was echoed by another student who described how putting knowledge in context through reflection helped him understand and retain knowledge:

I personally am an auditory learner so listening to content being placed in a context and then reflecting on that helps me through the learning process to not only retain information but to also understand and contextualize the content as well.

Through reflection, students personalized different learning theories and provided concrete contextual information about how to apply theories in practice. As one student indicated, reflection reveals students' personalized thinking of the theories:

The reflection session allowed me to gain better understanding of some theories that I was confused about. This opens a person's thinking about preconceived notions about different types of learning. We can apply these theories in practice by practicing what we preach because all theories are different and not all learning theories are universal.

\section{Providing Comparative References in Learning Through Collective Reflection}

Reflection reinforces students' understanding of other students' work. As one student stated, "before we reflect on other projects, we have to understand other projects ideas, designs, and theories." He further stated the benefit of reflection in helping students increase their knowledge:

Reflections on other projects is good to know what other students worked on. Having some idea about their project is so important to increase our knowledge in different designs, which can help build more practical information, before we reflect.

Reflection plays an important role for students to compare their projects with others and to see the differences and similarities. One student said that "Reading other students' reflections were interesting because they often had a different perspective than the way I thought about it. I think it is important to see the world through another lens." Another student shared a similar view about the role of reflection in helping students see the different perspectives : "Reflections of others 
helped me to see the theoretical ideas from the perspective of others; where we were in alignment and where we differed in our thought processes. It helps us to further realize our diversity."

Another student further stated how reflection pushes students to check each other's and thereby gain a wide variety of understandings of the knowledge that other students provided in their reflections:

By requiring that we review and provide reflection, we were encouraged to look at the work everyone was doing. This helped to get a wide understanding of each theory and possible ways that they could each be applied in the real world. It also ensured that we were given feedback from our peers and therefore given a different perspective for future facets of the project.

One student stated how reading others' reflections helped students learn the same knowledge in new and better ways:

I noticed that there was often an overlap in the reflections. Although we learned about something with one assignment didn't stop us from learning more with the next one. For example, communication is one lesson I repeated in the reflections. We constantly were learning new and better ways to effectively communicate with our group throughout the entire course.

Many students' reflections showed their particular ways of completing their projects, which served as references for other students. One student said: "I saw ways that other groups worked together and learned about their particular projects, which enabled me to steal some of their proven lessons for their learning style and their process as a group."

Students reflected on their experience in each assignment. However, there was still confusion in completing their assignments, especially in terms of the rationales for some assignments. I asked students to reflect on their experience in the mid-term reflection and share their struggles and expectations in the courses. I responded to students' questions, and at the same time shared the detailed rationales for why I had certain requirements for some assignments and reflected on the context of why I made such changes, as well as on the experiences of previous students. I also reflected on my struggles in teaching and my experience of teaching previous courses to provide more contextual information for the questions I asked in interviews. Such reflective dialogue with the interviewees helped students understand some concepts and help them to see the value of the assignments. For example, one student said:

I was a little confused on the monthly summaries, but when you explain it like that, it completely makes sense. And I think it's completely valid to have, and I think it's a valuable piece... So, it kind of shows our plan, and then we can see if our plan was successful that month, I guess? But it should show others how to organize their summaries that way. But I didn't look at it that way. But now that you say it, I'm like that's a good piece to incorporate.

I interviewed students every semester and revised the courses based on the feedback from the students. I reflected on the overall course design to find out the areas which needed improvement and the areas which should be integrated into the course design next time. When I noticed that most of the students did not do some assignments well or if the online discussions were not active, I knew that the courses were not designed well and needed improvements. 
In my online courses, one assignment connects to the next one, and the final assignment is the overview and demonstration of the previous assignments; reflection is embedded in each assignment. In each assignment, the assignment is divided into several steps, and reflection is the final step of the assignment. Such progressive design enables students to not only see the connections of each step in an assignment, but also the connections among assignments. Students had a chance to check each part of the knowledge they had learned in order to improve their future work. As one student said:

The reflection was an integral part of our project and allowed me personally to take a step back (so to speak) and think about the steps we took and how to move on any better the assignment at the next step.

Another student further stated how such design of the reflection helped students understand the connection of one step or one assignment to the overall structure of the knowledge they had learned: "It also demonstrated how each assignment fit into the overall process of learning, showing how each step worked in a structured timeline to provide the most complete and working understanding and application of our specific learning style."

Through reflection, students find social connections with each other and build relationship with others. One student said that "Reading the reflections from the other group members made us feel like we weren't alone. The reflections were very similar." Another student said that "Reading others' reflections allowed me to realize most people struggled with the same aspects and just how great my group really was." One student said that by sharing reflections with each other, students received positive comments from their classmates. Such actions "create a community amongst the learners within the course and that support system can be very beneficial especially in the online environment."

\section{Conclusions and Discussions}

Reflection plays an important role in promoting adults' learning. Reflection enables learners to question their actions, values, and assumptions (McClure, n. d.). Through reflection, learners reviewed and revisited the knowledge they had learned, explored the depth of the knowledge, and reinforced the knowledge. Reflection allows learners to step back to review the whole process of learning and to recognize the value of the knowledge holistically, not just fragments of knowledge.

Some students' reflections on their classmates' work mainly focused on emotional and social support, which are necessary for creating a collaborative and personalized learning environment. However, the value of reflection is more than just giving emotional and social support. In their reflections, students collectively shared some tacit information about how they conducted their projects in different ways, how they handled difficult situations, how they comprehended the course materials, etc. Such reflection helped students revisit and evaluate their own learning experiences, conceptualize the values and lessons gained in their learning, discover their learning gaps, and synthesize, abstract, and interpret the rationales for what they did and why they did it in certain ways (Bowne, et al., 2010). Such reflection requires students to be able to analyze, synthesize, and evaluate the knowledge they learned, which is a higher level of knowledge compared with the comprehension and application of the knowledge students gained through their projects (Bloom, 1956). 
In reflection, we recapitulate our actions and draw lessons from our past experiences (Schwarz, Dreyfus \& Hershkowits, 2004). Reflection enables students to rethink their experience in order to improve practice and change their perspectives (Freed, n. d.). This study shows that reflection helped students improve their work. Such improvement was shown in different ways. For example, through reflection, students could identify the areas that were not clear, look for the best strategies of completing their tasks, and identify the areas that were neglected by students. Students also improved the cohesiveness and the overall quality of their work. Reflection shared with the whole class enabled students to read others' reflections and understand each other's projects better. Such reflection also provided students an opportunity to offer meaningful feedback to each other and help each other improve their work in the future. Through reflections, students gained not only cognitive knowledge, but also knowledge which includes "facts and concepts, knowledge of procedures, and knowledge of conditions" (van Velzen, 2016, p. 23). Students also gained metacognitive knowledge - general knowledge about how learners process information and how learners understand their own learning process (Livingston, 1997).

"Reflection on the actions, thoughts and feelings that have arisen in a learning event can often provide an insight into learners' personal foundation of experience, into themselves, and into their ability to learn from this particular situation" (Boud \& Walker, 1990, p. 63). This study shows that reflection gives students an opportunity to personalize their learning and provide more contextualized information about their projects (Agouridas \& Race, 2007). In reflection, students were required to share the process of how they completed their assignments, through which the implicit knowledge became explicit. Such process description involves students' personal experiences and their understanding of the theories, as well as their emotional reactions to the events which occurred during the process of completing the projects. Such first-hand experience shared by peers provided the context for the theoretical knowledge, which is much easier for students to learn, and can help students find connections between theories and practice, since abstract knowledge contains little information relevant to the context from which abstract knowledge is derived. Such input information contains surface cues pointing to an abstract system that makes learning tasks simpler (Goschke, 1997). Reflecting on an event can also reveal learners' experiences and issues of which learners are not aware, which may lead to thoughts and actions that learners may not know of (Boud \& Walker, 1990). This is indicated in this study when reflection helped learners build personal connections between the theories and the community with which they were familiar.

Similar to the idea pointed out by some scholars (Krutka, et al., 2014), collective reflection among students brings different ideas and enhances students' learning from various perspectives. Reflection shared with the whole class enabled students to read others' reflections posted on their blogs and to understand each other's projects better. Such reflection also provided students an opportunity to offer meaningful feedback to each other in their group blogs and to help each other improve their work in the future. By reading their peers' reflections about how they completed their projects, students were able to compare their projects with their peers' projects, which provided students various new perspectives in learning. By reading others' reflections, students were able to use others' work as a reference and to identify the similarities and differences between their work and that of their peers, as well as to see how the same work could be completed through different approaches, viewed through different lenses, or addressed in a new and better way. Through comparison, students could relate their individual experience to a wider perspective and view their work within a bigger picture (Agouridas \& Race, 2007). I also reflected with students 
about the actions I took for course improvement, my rationale for the online teaching practice, the changes I made in the online courses over the years, and my experience with previous online courses, which clarified questions students may have been puzzled about, and also provided students references in terms of the changes in the online courses and the context and rationales for such changes. Such reflection helps students increase their meta-cognitive knowledge. Students with meta-cognitive knowledge "have the ability to think through their learning in advance in terms of which study and memorization techniques are likely to be most effective for them to learn a particular learning task" (van Velzen, 2016, p. 16).

This study indicates that reflection embedded in designed tasks can help learners see the interconnections of the knowledge they are learning. Reflection embedded in the progressive design of the assignment (one assignment serves as the foundation for the next one) allows students to see the structural connections within assignments. Students were able to see the shifts of knowledge from the concrete format to the generalized format, and how each portion of the assignment interconnected to the other portions, and how one assignment connected to the rest. Seeing such structural connections allows students to see how knowledge transforms hierarchically from one level to the next (Bloom, 1956).

Reflection also enabled students to find social connections among their fellow learners. Most of the students shared their emotions, their struggles, their communication problems, and the difficulties they had in doing their group work. When students shared the process of their work in their reflections, they found that their classmates had had similar experiences and struggles in their own learning. This made the students feel closer to their peers and helped strengthen their interconnectedness. Further, they gained the ideas of how to solve such problems when some peers shared their ideas of how they dealt with similar problems in their reflections. However, most students' reflections were at the stage of self-reflection and self-awareness (Yaffe, 2010), and were not raised to the stage of critical reflection and did not reach the conceptualized level of knowledge. Reflection should not just increase learners' self-awareness but should also help learners conceptualize their experience and extend their personal experience to a larger context (Kolb, 1984; Winitzky, 1992).

\section{Implications}

To facilitate reflection and to support learners in seeing the value of the knowledge they have learned and to reinforce the new knowledge, instructors can design assignments to include reflection. Specifically, at the end of each assignment, instructors can ask students to reflect on the process and value of the projects they have completed and conceptualize the lessons they have gained to improve their projects. Such reflection on past actions (Roskos, Vukelich, \& Risko, 2001) will require students to revisit their learning and discover its value as well as the issues that were missed.

To improve learners' meta-cognitive knowledge though reflection, instructors can design prompt questions for the reflection, such as: What have you missed in your assignment? Which parts of your assignment were not clear to you? What could you do to improve your work? What would you do differently, if you could redo your assignment? Instructors should encourage students to perform critical reflection of other students' work posted in their blogs by comparing their work with their peers, and by pointing out the limitations of their peers' work. Instructors can also provide examples from previous courses as references to show students the changes to the present course compared with previous courses, and the rationales for such changes. Such 
reflection shared with students aims to help students understand the methodology and techniques used to support their learning and to increase students' meta-cognitive knowledge (van Velzen, 2016).

Personalizing knowledge and providing contextualized knowledge help learners understand the abstract theories and how the knowledge they have learned relates to the practical field (Agouridas \& Race, 2007, Boud \& Walker, 1990, \& Lamberts \& Shanks, 1997). To help learners personalize and contextualize their learning, instructors can ask students to share the experience of how they completed their project, as well as how they understand the theories by demonstrating their own projects and by showing their peers the process and rationales for their projects in videos. Such reflection gives students the opportunities to share their "explicit and tacit knowledge" (Gausdal, 2008, p. 211) with their peers and allows their peers to see the knowledge that is otherwise hidden. Educators can help learners externalize their tacit mental activities by prompting them to reflect on what they have done before, during or after their learning activities (Lin et al., 1999). Instructors can require learners to reflect on content-specific knowledge and process. To personalize the theory, instructors can ask students to reflect on which ideas in their projects remind them of their own experience, and how. Students can also reflect on daily practice, events, behaviors, etc. Such reflection focuses on both professional and private issues and can be facilitated by data from external resources, such as events produced electronically, structured feedback, or feedback from other persons (Kottkamp, 1990).

Technology can also help learners make the tacit learning process explicit by showing what they have done and how. For example, learners can use tools such as video and graphics to not only document the process of how they solved the problems, but also how they traced, recorded, and visually displayed their educational products.

To contextualize knowledge often involves revealing more personal information. This requires an environment which makes students feel comfortable and feel connected (Nilsson, Andersson, \& Blomqvist, 2017), especially in an online environment where it is hard for students to be open to each other due to the lack of a physical interactions (Chang \& Kang, 2016). The instructor can encourage students to reflect on the struggles they had and their emotional and personal stories in the process of their learning. Students can find connections through such stories and can easily get connected to each other. In terms of what to reflect on to help students build connections with each other, instructors can recommend the following: the management system that students used to manage their projects and budget their time and group resources, the methodology such as how students approached their projects and how they completed their process; their emotional experience, such as how they struggled in the course, and what kind of difficult situations they had, and how they solved these difficult situations. Other students may find the connections to some of these experiences and gain knowledge and trust from such reflections.

To help students see the structural connection of the assignments, instructors can embed reflection in each assignment. The instructors can design these assignments based on the interconnections of these assignments and the learning objectives they would like students to achieve, and ask students to reflect on their learning process and how one assignment contributes to another in the final electronic demonstration. Presenting the educational product is also an act of reflection, since learners can review the list of what they have completed and reflect on the process of how they conveyed the ideas in their product (Lin et al., 1999). The instructor can also divide each assignment into several major parts and ask students to summarize the main ideas of each part in a table at the end of each assignment. Such evaluative reflection serves as a checklist 
for students to review each part of the knowledge they had learned and helps students see their learning product from the holistic perspective.

\section{Educational Importance of the Study}

This study contributes to the practice of online learning by pointing out how reflection impacts learning and helps learners to learn by increasing the depth of knowledge, identifying the areas that need improvement, personalizing and contextualizing knowledge, providing comparative references in learning, and helping learners see the structural connections in knowledge and creating social connections among them. This study provides foundational ideas for designing reflective activities to promote students learning in an online learning environment. This study also provides practical suggestions about how to embed reflections in learning activities to support students' gaining different levels of knowledge. 


\section{References}

Agouridas, V., \& Race, P. (2007). Enhancing knowledge management in design education through systematic reflection in practice. Concurrent Engineering, 15 (1), 63-76.

Berrill, D. P., \& Addison, E. (2010). Repertoires of practice: Re-framing teaching portfolios. Teaching and Teacher Education, 26(5), 1178-1185. doi:10.1016/j.tate.2010.02.005

Bloom, B.S. (1956). Taxonomy of educational objectives: The classification of educational goals. New York, NY: Longmans.

Boud, D., \& Walker, D. (1990). Making the most of experience. Studies in Continuing Education, 12(2), 61-80. doi:10.1080/0158037900120201

Bowne, M., Cutler, K., DeBates, D., Gilkerson, D., \& Stremmel, A. (2010). Pedagogical documentation and collaborative dialogue as tools of inquiry for pre-service teachers in early childhood education: An exploratory narrative. Journal of the Scholarship of Teaching and Learning, 10 (2), 48 - 59.

Chang, B., \& Kang, H. (2016). Challenges facing group work online. Distance Education, 37(1), 7388. doi:10.1080/01587919.2016.1154781

Clark, H. H., \& Brennan, S. E. (1991). Grounding in communication. In L. B. Resnick, J. M. Levine, \& S. D. Teasley (Eds.). Perspectives on socially shared cognition (pp. 127-149). Washington DC: American Psychological Association.

Elo, S., \& Kyngäs, H. (2008). The qualitative content analysis process. Journal of Advanced Nursing, 62(1), 107-115. doi:10.1111/j.1365-2648.2007.04569.

Freed, S. A. (n. d.). Metaphors and reflective dialogue online. Retrieved from http://www.andrews.edu/ freed/MetaphorsOnlinel.pdf

Gausdal, A. H. (2008). Developing regional communities of practice by network reflection: The case of the Norwegian electronics industry. Entrepreneurship \& Regional Development, 20(3), 209-235. doi:10.1080/08985620701748367

Goschke, T. (1997). Implicit learning and unconscious knowledge: Mental representation, computational mechanisms, and brain structures. In K. Lamberts, \& D. R., Shanks (Eds.). Knowledge, concepts, and categories (pp. 247-333). Cambridge, Mass: MIT Press.

Helyer, R. (2015). Learning through reflection: The critical role of reflection in work-based learning (WBL). Journal of Work-Applied Management, 7(1), 15-27. Retrieved from https://doi.org/10.1108/JWAM-10-2015-003

Helyer, R., \& Kay, J. (2015). Building capabilities for your future. In Helyer, R. (Ed.), The Workbased learning student handbook (2nd ed., pp. 31-50). Palgrave.

Kolb, D. A. (1984). Experiential learning: Experience as the source of learning and development (Vol. 1). Englewood Cliffs, NJ: Prentice-Hall.

Kottkamp, R. B. (1990). Means for facilitating reflection. Education and Urban Society, 22 (2), 182203.

Krutka, D. G., Bergman, D. J., Flores, R., Mason, K., \& Jack, A. R. (2014). Microblogging about teaching: Nurturing participatory cultures through collaborative online reflection with preservice teachers. Teaching and Teacher Education, 40, 83-93. doi:10.1016/j.tate.2014.02.002 
Larsen, D. P., London, D. A., \& Emke, A. R. (2016). Using reflection to influence practice: Student perceptions of daily reflection in clinical education. Perspectives on Medical Education, 5(5), 285-291. doi:10.1007/s40037-016-0293-1

Lin, X., Hmelo, C., Kinzer, C. K., \& Secules, T. J. (1999). Designing technology to support reflection. Educational Technology Research and Development, 47(3), 43-62. doi:10.1007/BF02299633

Livingston, J. A. (1997). Metacognition: An overview. Retrieved from http://gse.buffalo.edu/fas/shuell/cep564/metacog.htm

McClure, P. (n. d.). Reflection on practice. Retrieved from http://www.supervisionandcoaching.com/pdf/Reflection\%20on\%20Practice\%20(McClure\%2 Oundated).pdf

Nilsson, M., Andersson, I., \& Blomqvist, K. (2017). Coexisting needs: Paradoxes in collegial reflection - The development of a pragmatic method for reflection. Education Research International, 2017, 1-12. doi:10.1155/2017/4851067

Ovens, A., \& Tinning, R. (2009). Reflection as situated practice: A memory-work study of lived experience in teacher education. Teaching and Teacher Education, 25(8), 1125-1131. doi:10.1016/j.tate.2009.03.013

Persson, E. K., Kvist, L. J., \& Ekelin, M. (2018). Midwifery students' experiences of learning through the use of written reflections - An interview study. Nurse Education in Practice, 30, 73-78. doi:10.1016/j.nepr.2018.01.005

Polit, D. F., \& Beck, C. T. (2010). Generalization in quantitative and qualitative research: Myths and strategies. International Journal of Nursing Studies, 47(11), 1451-1458. doi:10.1016/j.ijnurstu.2010.06.004

Roberts, C. (2008). Developing future leaders: The role of reflection in the classroom. Journal of Leadership Education, 7(1), 116-130. doi:10.12806/V7/I1/AB1

Roskos, K., Vukelich, C., \& Risko, V. (2001). Reflection and learning to teach reading: A critical review of literacy and general teacher education studies. Journal of Literacy Research, 33(4), 595-635. doi:10.1080/10862960109548127

Schon, D. A. (1987). Educating the reflective practitioner: Toward a new design for teaching and learning in the professions. San Francisco: Jossey-Bass

Schwarz, B., Dreyfus, T., \& Hershkowits, N. H. R. (2004) . Teacher guidance of knowledge construction. Proceedings of the 28th Conference of the International Group for the Psychology of Mathematics Education, 4, 169-176. Retrieved from http://www.kurims.kyotou.ac.jp/EMIS/proceedings/PME28/RR/RR175 Schwarz.pdf

van Velzen, J. (2016). Metacognitive learning: Advancing learning by developing general knowledge of the learning process (1st ed.). Cham: Springer. doi:10.1007/978-3-319-24433-4

Winitzky, N. (1992). Structure and process in thinking about classroom management: An exploratory study of prospective teachers. Teaching and Teacher Education, 8(1), 1-14. doi:10.1016/0742-051X(92)90036-3

Yaffe, E. (2010). The reflective beginner: Using theory and practice to facilitate reflection among newly qualified teachers. Reflective Practice, 11(3), 381-391. doi:10.1080/14623943.2010.490070 